\title{
Transformational Leadership and Innovative Strategies Influencing Startup Performance
}

\author{
S. Sangeetha, R. Shanthi
}

\begin{abstract}
Startups are coming up with their entrepreneurial ambitions. Individual firms extend into larger businesses with an urge to fulfil their business needs. It is possible when startups put their effort into business with their leadership and technological skills. Some of the earlier studies have proved that the economic growth of a developed country is purely because of the quality and efficiency of the entrepreneurs. Generally persons with entrepreneurial ambitions have highest potential to generate new jobs in the economy. Startups personal characteristics, skills and competency are necessary for them to compete and survive in the business environment. Knowledge and new ideas are often outcomes of the entrepreneurs. This study explains the leadership skills and management strategies of the startups and also analyse the startups performance in relation to their leadership skills, management strategies.
\end{abstract}

Keywords : startups, leadership skills, strategies, performance.

\section{INTRODUCTION}

$\mathrm{T}_{\mathrm{r}}$ ransformational leaders increases the morale, motivation and job performance of followers through different mechanisms. Transformational leaders motivate their employees to reach organisational goals (Hill, 2012).Transformational leadership is applicable to startups. There has been a significant transformation in organisations through diverse change in technology and international competition (Smit et al, 2005). Startups as a leader works with their teams to create a vision to guide the change through stimulation, identify the necessary changes needed in the society and execute it with the dedicated group members.

Chennai is one of the Indian cities with most skilled and talented individuals. Initially the city started developing as a successful place for automobile startups and now it is gradually becoming a SaaS hub and attracting the entrepreneurs from every field including engineering and manufacturing. Competitive and hassle-free climate makes Chennai the renowned market for business aspirants. 15 The business and trade laws are different in the areas like Special Economic Zones (SEZ). There are 55 such zones operational in Tamil Nadu, out of which 18 are in Chennai. In addition, the city's standard of living makes it the most ideal destination for startups.

Revised Manuscript Received on December 05, 2019.

* Correspondence Author

S.Sangeetha*, Ph.D Research Scholar, Department of Commerce, University of Madras, Chennai, India. Email: san.1994@ymail.com

Dr. R. Shanthi, Associate Professor, Department of Commerce, University of Madras, Chennai, India. Email: rshanthicommerce@gmail.com

\section{REVIEW OF LITERATURE}

Sambasivan, Abdul, \& Yusop, (2009)addressed the impact of individual qualities of entrepreneurs qualities, opportunity recognition and management skills on their business performance. The study results indicated that opportunity recognition skills influenced business performance as a moderator between entrepreneur's skills and qualities. Volume of sales, growth of sales and profit stability were used as elements of business performance.

Ye, Q. (2018) examined the effect of collaborating experienced and skilled entrepreneurial team and startups resources on their firm's performance. Based on the study findings, finance plays an important role on startup firms' profitability, but it has negative impact at the early stage of starting a venture. The study concluded that small size startups firms yield good returns than large organisations.

Dyer, (2008) examined the features of innovative entrepreneurs and found the elements of innovative strategies adopted by them. This article developed a model describing the differentiating innovative entrepreneurs from administrative executives on four behavioural pattern by way of questioning, observing, idea networking and experimenting. This article concluded that individual's capability to develop new ideas for innovative businesses is in action of individual's behaviour that induce cognitive processes to gerate new business ideas.

Tehseen, \& Ramayah, (2015) studied the entrepreneurial skills on the success of their business. This paper argued that the external integration controls the impact of entrepreneurial skills on their SME's business success. Entrepreneurs should manage their relationships with their suppliers and customers to get competitive advantage. Hence, it results in business success and survival.

\section{RESEARCH QUESTIONS}

1. What are the role of transformational leaders in the success of business?

2. Howbusiness innovative strategies influence startup performance?

\section{OBJECTIVE}

1. To understand the role of transformational leaders in the success of business.

2. To analyse the impact of business innovative strategies on startup performance. 


\section{LEADERS ROLE IN BUSINESS SUCCESS}

Startups as a transformational leader implements an efficient grouping of holistic and individualistic approaches to reach the common objective and goals of a group (Muralidaran and Pathak, 2018). Transformational leaders create noteworthy changes in the organisation's mission, vision, attitude, strategy and values by innovation and technologies in their products and services.

There are lot of things that makes a successful business, but leadership is one of the main reasons for the business success. Startups as a leader create the organisational vision, purpose and goals that every person involved in the firm works together for achieving the target. They motivate the team and lead employees to accomplish targeted mission, vision and milestones. Startup need to improve their skills constantly, even experienced leaders are pursue them to ongoing business training. Since change is endless, it is a part of present day business.It made the startups to directtheir teams and organisations through changeover.

\section{STARTUPS INNOVATIVE STRATEGIES}

Innovation comes out in a way of creative thoughts with new idea, in any form of method or device. Innovation is also seen as a remedy of better solutions that meet the market needs (Wikipedia).Innovation strategy enhance profits or grows market share through innovative products and/or services. It should also specify, whether a product need an improvement or breakthrough innovation approach, when it comes to create a solution.

Due to rapid change in business developments, the business firms are at significant risk of being left behind. Innovation is an important element for entrepreneurship, in the highly competitive world. To build customer network, a company has to create a strong brand and outstanding product through innovation. It is necessary for startups to adopt innovative strategies that help them to compete and survive in the business environment. It made startups to do something new and innovative to exploit opportunities. For this, startups has to craft strategies to their business practices, processes and the decision-making styles. Adopting innovative strategy is the initial step by an organisation for competitive uniqueness. The strategic activities includes industry and market analysis, product and service designs, its operations, customer development, technology management and other various levels of the new business's culture, shared values and vision. Startups management strategy is affected by initial capital investments, limited resources, etc. than established firms. They face several challenges and uncertainties such as customer demand, dynamic technological changes, indistinct products and its features, and extreme vagueness about business opportunities that reduces their chance of survival and success.

\section{RESEARCH METHODOLOGY}

Qualitative and quantitative data were used in this study. Survey has been conducted with 85 startups in Chennai. Questionnaire is used as a tool to collect the data from respondents. Schedule method has been followed most of the time. Snowball sampling method was adopted to collect the data. Pilot study has been made to scrutinize the questionnaire. After modifying some of the questions, the questionnaire is set for data collection.

\section{ANALYSIS AND INTERPRETATION}

The startups demographic profile were analysed through percentage analysis. Reliability test was analysed to know the scale validity. Factor analysis were performed to analyse the impact of business innovative strategies on startup performance.

The result of percentage analysis from the sample of 85 respondents were summarized below:

- $61.2 \%$ of the respondents are male and others are female $(38.8 \%)$.

- $48.2 \%$ of the respondents are at the age of 25 to 35 years, followed by 36 to 45 years $(30.6 \%)$, above 45 years $(15.3 \%)$ and few are below 25 years $(5.9 \%)$.

- Most of the startups have done professional courses $(51.8 \%)$, followed by post graduate $(30.6 \%)$ and Graduate (17.6\%).

- Most of the startup companies are operating their business for more than 6 years $(67.1 \%)$, followed by 1 to 3 years $(18.8 \%), 4$ to 6 years $(11.8 \%)$, and less than 1 year $(2.4 \%)$

- Most of the startup companies have less than 20 employees $(64.7 \%)$, followed by 20 to 40 employees (25.9\%), 40 to 60 employees $(3.5 \%)$ and few companies have more than $60(5.9 \%)$.

\section{A. Result of Reliability Test}

Table - 1: Table showing reliability statistics

\begin{tabular}{|c|c|}
\hline \multicolumn{2}{|c|}{ Reliability_Statistics } \\
\hline Cronbach's_Alpha & No._of_items \\
\hline 0.916 & 21 \\
\hline
\end{tabular}

Cronbach's alpha coefficient is used to identify scale reliability. A value of Cronbach's alpha above 0.70 is a reasonable test for scale reliability. By applying Cronbach's Alpha test for 21 items, it is observed that the overall Cronbach's alpha co-efficient were 0.916 which is considered as good level.

\section{B. Result of Factor Analysis}

Table - 2: Table showing KMO and Bartlett's Test

\begin{tabular}{|c|c|c|}
\hline \multicolumn{3}{|c|}{ KMO_and_Bartlett's_Test } \\
\hline \multicolumn{2}{|c|}{ Kaiser-Meyer-Olkin Measure of Sampling Adequacy. } & 0.767 \\
\hline \multirow{2}{*}{ Bartlett's_Test_of_Sphericity } & Approx. Chi-Square & 1354.683 \\
\cline { 2 - 3 } & df & 210 \\
\cline { 2 - 3 } & Sig. & 0.000 \\
\hline
\end{tabular}

The table shows that the range of KMO sampling adequacy value of 0.673 and Chi-square value of 565.185 at degree of freedom 91 with p-value (significance) of 0.000 in Bartlett's Test of Sphericity. Since the value are nearer to 1, it is consider as better and so is it suitable for performing 
factor analysis.

Table - 3: Table showing total variance explained

\begin{tabular}{|c|c|c|c|c|c|c|}
\hline \multirow{2}{*}{ Component } & \multicolumn{3}{|c|}{ Initial_Eigenvalues } & \multicolumn{2}{c|}{ Rotation_Sums_of_Squared_Loadings } \\
\cline { 2 - 7 } & Total & $\begin{array}{c}\text { Percentage_of_ } \\
\text { Variance }\end{array}$ & Cumulative_percentage & $\begin{array}{c}\text { Percentage_of_ } \\
\text { Variance }\end{array}$ & 25.790 \\
\hline 1 & 8.133 & 38.727 & 38.727 & 5.416 & 20.940 \\
\hline 2 & 2.563 & 12.202 & 50.930 & 4.397 & 13.466 \\
\hline 3 & 1.946 & 9.266 & 60.196 & 2.828 & 46.729 \\
\hline
\end{tabular}

The total variance explained is 74.04 percentage. All the three factors are explained with the variance $25.79 \%, 20.94$ $\%$ and $13.47 \%$. This variance leads to variable loading of each factor that is responsible for the impact of startups business performance and success. This leads to the sub-division of factors by grouping the variables as shown in the rotated component matrix.

Table No.4: Table showing factor loadings

\begin{tabular}{|c|c|c|c|c|}
\hline $\begin{array}{l}\text { Factor } \\
\text { Name }\end{array}$ & $\begin{array}{c}\text { Factor } \\
\text { Loading }\end{array}$ & $\begin{array}{c}\text { Total Factor } \\
\text { Loadings }\end{array}$ & $\begin{array}{c}\text { Cronbach's } \\
\text { Alpha }\end{array}$ & $\begin{array}{c}\% \text { of } \\
\text { variance }\end{array}$ \\
\hline \multirow{11}{*}{$\begin{array}{l}\text { Innovative } \\
\text { Business } \\
\text { Strategy }\end{array}$} & 0.866 & \multirow{11}{*}{6.645} & \multirow{11}{*}{0.917} & \multirow{11}{*}{$25.79 \%$} \\
\hline & 0.811 & & & \\
\hline & 0.795 & & & \\
\hline & 0.747 & & & \\
\hline & 0.739 & & & \\
\hline & 0.692 & & & \\
\hline & 0.677 & & & \\
\hline & 0.674 & & & \\
\hline & 0.644 & & & \\
\hline & 0.754 & & & \\
\hline & 0.722 & & & \\
\hline \multirow{8}{*}{$\begin{array}{l}\text { Business } \\
\text { performance }\end{array}$} & 0.809 & \multirow{8}{*}{5.421} & \multirow{8}{*}{0.880} & \multirow{8}{*}{$20.94 \%$} \\
\hline & 0.786 & & & \\
\hline & 0.735 & & & \\
\hline & 0.715 & & & \\
\hline & 0.660 & & & \\
\hline & 0.585 & & & \\
\hline & 0.579 & & & \\
\hline & 0.552 & & & \\
\hline \multirow{3}{*}{$\begin{array}{l}\text { Startup } \\
\text { Leadership } \\
\text { skill }\end{array}$} & 0.799 & \multirow{3}{*}{2.275} & \multirow{3}{*}{0.756} & \multirow{3}{*}{$13.47 \%$} \\
\hline & 0.754 & & & \\
\hline & 0.722 & & & \\
\hline
\end{tabular}

The factors are loaded at 0.40 and above are given in the above table. From the overall factor loadings, the factors are ranged from 0.552 to 0.866 and the extracted factors were named based on the loaded items. The Cronbach alpha value for each factor is mentioned separately above. Since, all the alpha value is above 0.70 it shows good reliability scale.

Innovative Business Strategy: First factor have been extracted with nine variables with $25.79 \%$ of variance. Since the statements related to the factor includes innovativeness, opportunity seeking, adoption of new techniques and instruments in business process, trending with market needs, etc. it is named as "innovative business strategy". The Cronbach alpha value for the factor is 0.917 and the value of total factor loading is 6.645. The each and every strategy of the startup leads to improve in employees' capability, improves organisation productivity and improves employees' consistency.

Business Performance: The second dominating factor is explained with the variance of $20.94 \%$ with eight variable with total factor loading of 5.421 and its Cronbach alpha value for the factor is 0.880 . The statement related to the factor includes sales growth, return on investment, customer satisfaction, valuing customers, etc. Hence, the factor is named as "business performance" Normally business performance is analysed based on the strategic decisions taken by the business owners. The performance improves based on the business profitability, engaging employees into business, enhancing skills, financial performance, customer satisfaction and customer retention.

Startup Leadership Skill: The third dominating factor is explained with the variance of $13.47 \%$ with three variables. The statements related to the factors are seeking opportunity, lead and encourage employees towards organisational goals, competitive and creative. Since, the factor is named as "startup leadership skill". The variables under the value of 0.40 were not taken into consideration. The Cronbach alpha value for the factor is 0.756 and the value of total factor loading is 2.275.The first and foremost leadership skill that a startup should have is willingness to innovate and taking risk. Since the business environment is dynamic, they must be flexible in both good and tough times.

From the above interpretation, it can be summarized that, the leadership skills and innovative business strategy leads to successful business performance for the startups. It does not based on the size of the firm. When the performance of the employees are poor, the organisation also performs poorly. When the employees perform well, the organisation also outshines. In that way a startup needs leadership skills and innovative business strategy to improve the performance of the employees. Since, the business performance is depend upon the strategy adopted by the company. Startup must monitor the customer preference and needs, competitors' actions, technological development, and the internal process of business performance, as well as develop appropriate innovative business strategies. The business performance might differ from period or over long time period due to changes in business strategies.

\section{Published By:} Blue Eyes Intelligence Engineering 


\section{IMPLICATION}

Technology and innovation, has changed the lives of the people drastically, in its revolutionary and evolutionary form. Some of the products and services have changed the lives the way people live. It is a result of revolutionary innovation. Renowned innovation by great leaders have made this possible. There is a quick reaction in adopting the changes. Several changes were not in the memory about what it was like actually before; even though such products and services are into the lives of the people. There are some products, of these innovative organisations that influence the lives of the people in a more unrecognizable evolutionary way. When these startups grow, they directly impact the growth of their cities. Increase in youth employment opportunities and new employment patterns came into existence. Passionate youngsters pursue with new opportunities and experienced and talented persons started moving to these cities in search of a high-growth and challenging career. It will not only create the next generation innovators and technologists but also create a revolution in the industries.

\section{CONCLUSION}

Startupsare innovative and favourable to the economic growth. Certainly, leadership, new business formation and innovation, are the key drivers of the growth of our economy. Starting up a business would not make a person as a leader. Leaders not only exists with more numbers of employees or followers, but a changeover in the economy makes them a leader. The changeover starts from startup entrepreneurs and wash out unemployment and underemployment. Only innovative startups transform their business activities in industries and lead to increase in productivity and jobs. Moreover, while innovative products ensure early success, product innovators should also develop innovative processes to ensure their businesses' survival.

Startups who wants to sustain in business environment should look out for opportunities to improve their leadership skills and innovative business strategies in their business venture. The study examined the transformational leadership and the impact of innovative strategies on startup performance. The study findings showed the factors influencing startups business performance. Therefore, it is concluded that startup business success depend on their leadership skills, innovative business strategies and business performance.

\section{REFERENCES}

1. Baumol. W. J, (2002) Entrepreneurship, Innovation and Growth - The David Goliath symbiosis,Journal of Entrepreneurial Finance, 7(2), 1-10

2. Dyer. J. H, Gregersen. H. B, and Christensen. C, (2008) Entrepreneur Behaviours, opportunity recognition, and origins of innovative ventures,Strategic Entrepreneurship Journal, 2(4), 317-338

3. Hill N Sharon, Myeong-Gu Seo, Jae Hyeung Kang, and M. Susan Taylor, 2012 Building employee commitment to change across organizational levels - The influence of hierarchical distance and direct managers'transformational leadership, Organization Science 23: 758-77

4. www.ecosysteminsights.org/startup-activity-is-not-inherently-good/.

5. www.entrepreneur.com/article/324456.

6. Hughes. A, (2001) Innovation and business performance - small entrepreneurial firms in the United Nations and the European Union,New Economy, 8(3), 157-163
7. Kiptui. J, (2009) The role of organizational Culture in the Relationship between Strategy and Performance of Commercial banks in Kenya.

8. Muralidharan. E and Pathak. S, (2018) Sustainability, transformational leadership, and social entrepreneurship,10(2), 567

9. Sambasivan. M, Abdul. M, \& Yusop. Y, (2009). Impact of personal qualities and management skills of entrepreneurs on venture performance in Malaysia - Opportunity recognition skills as a mediating factor,Technovation, 29(11), 798-805

10. Smit. E, De Coning. T. Jand Visser. D. J, (2005) The relationship between the characteristics of the transformational leader and the entrepreneur in South African SMEs,South African Journal of Business Management, 36(3), 51-63

11. Tehseen. S and Ramayah.T, (2015) Entrepreneurial competencies and SMEs business success - The contingent role of external integration,Mediterranean Journal of Social Sciences, 6(1), 50

12. Ye, Q (2018). NewBorn Startups Performance: Influences of Resources and Entrepreneurial Team Experiences, Electronic Business, 17(4).

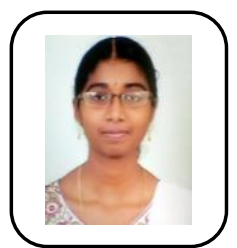

\section{AUTHORS PROFILE}

S. SANGEETHA, pursuing doctoral research in the area of entrepreneurship in the department of Commerce, University of Madras, Chennai, under the guidance of Dr. R Shanthi. She has completed M.com, first class with distinction. She worked as a project assistant in UGC- major research project. She has participated and presented papers in various National and International Conferences and also participated in many Workshops. She has published paper in National and International Conferences referred journals. She has acted as an organising member for National Seminars. She received best research paper award for the paper titled "Role of Information Technology in Nurturing Millennial Startups" in an international conference.

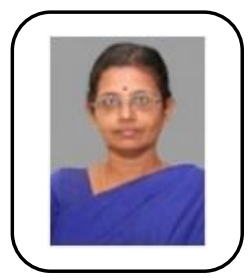

Dr. R. Shanthi is presently Associate Professor, Department of Commerce, University of Madras, Chennai. She has over 20 years of experience in the realm of marketing and banking. She has published paper in peer reviewed journals, Newspaper and Edited Books. She has authored a book on Customer Relationship Management, advanced marketing, data analytics using SPSS and AMOS and also organised three international conferences and four at national level. She has conducted training for corporate service on customer satisfaction and brand equity. She has undertaken UGC - Major Research Projects. She is acting as Doctoral committee member for various university and colleges. She is in the examination board for affiliated college and University and a recipient Award for "Meritorious Services, Outstanding Performance and Remarkable Role" rendered in the Academic field. 